\title{
Burocratas, carreira e diplomacia: uma análise das trajetórias da elite do Ministério das Relações Exteriores
}

Rodolfo de Camargo Lima

Universidad Católica de Temuco (UCT), Chile

\begin{abstract}
Como se desenham as trajetórias das carreiras dos diplomatas de elite do Ministério das Relações Exteriores (MRE)? Considerando que os trânsitos institucionais dos diplomatas brasileiros constituem peça central no funcionamento administrativo e político dessa burocracia, o presente artigo tem como objetivo responder a essa pergunta. Isso porque analisar essas dinâmicas colaboram tanto para entender um dos ministérios mais fechados do serviço civil público nacional, quanto avançam na construção de padrões da movimentação institucional dos atores que operam, sistematicamente e desde posições de comando, a política externa brasileira. Assim, a carreira da elite diplomática, composta por segundos ministros e embaixadores, e por mais de três décadas de carreira em média de carreira, é descrita em termos tanto das indicações para cargos de confiança na Secretaria de Estado (Sere), quanto nas passagens por postos diplomáticos no exterior, instituições nacionais e organismos internacionais. Os resultados apontam para um comportamento muito similar entre as duas hierarquias em que a maioria dos cargos de confiança na Sere são direcionados a posições de nível intermediário (DAS-4). As frequências majoritárias das trajetórias exógenas a Sere, se concentram em postos no exterior, de classes " $A$ " $e^{~ " ~} C$ ", seguidas por trânsitos em organismos internacionais e difusamente por instituições nacionais.

Palavras-chave: diplomatas, Ministério das Relações Exteriores, carreira pública, elite burocrática, política externa.
\end{abstract}

[Artigo recebido em 30 de junho de 2016. Aprovado em 23 de julho de 2019.] 


\section{Bureaucrats, career and diplomacy: a trajectory analysis of the Ministry of Foreign} Affairs elite

How the Brazilian Ministry of Foreign Affairs (MFA) elite diplomats design their careers? Considering that Brazilian diplomats' institutional turnover is central to the ministry administrative and political functioning, this investigation aims to answer this question. On the one hand, analyzing these dynamics collaborates to understand how one of the closest ministries of the national public civil service works. On the other, the article advances in the institutional trajectory patterns of the actors that operate, systematically and from the top, the Brazilian foreign policy. Therefore, the diplomatic elite career, being second ministers and ambassadors, throughout more than three decades on average, is described as the political appointments within the Department of State (DoS), as the turnovers in diplomatic posts, national institutions, and international organizations. The results point out to a similar behavior between the two hierarchies in which the most political appointments in DoS are to intermediate-level positions (DAS level 4). The primary trajectory frequencies outside DoS, aims to diplomatic posts, " $A$ " and " $C$ " class types, followed by international organizations and diffusely to national institutions.

Keywords: diplomats, Ministry of Foreign Affairs, public career, bureaucratic elite, foreign policy.

\section{Burócratas, carrera y diplomacia: un análisis de la trayectoria de la élite del Ministerio de Relaciones Exteriores}

¿Como se diseñan las trayectorias de las carreras de diplomáticos de elite del Ministerio de las Relaciones Exteriores de Brasil (MRE)? Considerando que los tránsitos institucionales de los diplomáticos brasileños constituyen pieza fundamental para el funcionamiento administrativo y político de esa burocracia, el presente artículo tiene como objetivo responder a esa pregunta. Eso porque analizar esas dinámicas colaboran tanto para entender uno de los ministerios más cerrados del servicio público nacional cuanto avanzan en las construcciones de patrones de transito institucional de los actores que operan sistemáticamente y desde las posiciones de comando, la política externa brasileña. Así la elite diplomática, compuesta por segundos ministros y embajadores, por más de tres décadas de carrera en promedio, es describa en términos tanto de las indicaciones para cargos de confianza en la Secretaria de Estado (Sere) cuanto en sus pasajes por puestos diplomáticos en el exterior, instituciones nacionales, y organismos internacionales. Los resultados apuntan para un comportamiento muy similar entre las dos jerarquías en que la mayoría de los cargos de confianza son direccionados a posiciones de nivel intermediario (DAS-4). Las frecuencias mayoritarias de las trayectorias exógenas a Sere, se concentran en puestos en exterior, de clases " $A$ " y " $C$ ", seguidas por tránsitos en organismos internacionales y difusamente por instituciones nacionales.

Palabras-clave: diplomáticos, Ministerio de las Relaciones Exteriores, carrera publica, elite diplomática, política externa. 


\section{Introdução}

Como se constroem as trajetórias da elite diplomática brasileira? A despeito de muitas lacunas nos estudos sobre o Poder Executivo nacional (FIGUEIREDO, 2010; LOUREIRo et al. 2010), e ainda que se conheça pouco sobre o comportamento burocrático no mundo (OLIVEROS; SCHUSTER, 2018), o presente artigo pretende lançar luz sobre essa face da dinâmica político-burocrática do Ministério das Relações Exteriores (MRE ou Itamaraty) do Brasil. Isso porque, ao se conhecer mais sobre as trajetórias de sua elite, podemos entender, mesmo que inicialmente, parcelas do processo institucional que se relacionam ao serviço público oferecido por essa burocracia, por entre as trajetórias de atores que são centrais na operação da política externa nacional.

Nesse aspecto, a pesquisa mira descrever a alocação institucional dos diplomatas pertencentes à elite do Itamaraty, vulgo segundos ministros e embaixadores. $\mathrm{O}$ artigo inclui, portanto, os trânsitos desses atores pela própria burocracia do MRE composta pela Secretaria de Estado (Sere), via nomeação para cargos de confiança ("DAS"), e as frequências de suas trajetórias nas demais unidades diplomáticas no exterior, e também para fora do âmbito da chancelaria, em instituições nacionais e internacionais, ao longo de mais de três décadas de carreira desses servidores de elite, em média. Reitera-se que, nesse quadro, existem, de um lado, múltiplos incentivos institucionais - desde fast-tracks para promoções, até regras e pré-requisitos para os desenhos das carreiras -, entre outras demandas e constrangimentos por parte do Itamaraty, para que sejam cumpridos os interesses, metas e objetivos políticos e burocráticos do próprio ministério, em mandatos direcionados aos atores que operam a instituição. De outro, estão as ambições e motivações dos próprios diplomatas, que miram construir suas trajetórias e carreira, com base em suas preferências individuais, pessoais e políticas.

Evidentemente que essa equação agente-estrutura é demasiado complexa, e o artigo não se debruça especificamente nessa cara equação às Ciências Sociais. Entretanto, oferece-se aqui a intuição de que é por entre esse delicado equilíbrio que se estabelecem as bases que garantem a manutenção e o funcionamento do próprio ministério, e a partir da descrição das trajetórias, podemos, de modo exploratório, entender mais sobre as prioridades e preferências dessa burocracia. As trajetórias serão desenhadas e apresentadas a seguir, utilizando-se de um banco de dados original com todos os currículos do anuário de pessoal do MRE (Diplomatas 2010), construído pelo autor, que inclui a elite diplomática, composta por 235 segundos ministros e 186 embaixadores. 
Reitera-se que a análise empírica descreve as trajetórias, que vão desde a entrada do indivíduo na carreira, vulgo o ano de sua turma no curso de formação do Instituto Rio Branco ( $\mathrm{RBBr}$ ), até o último ano de atualização do banco em 2010. Na primeira parte do artigo, o referencial teórico reforça sumariamente os aspectos relacionados à institucionalização do Itamaraty, da profissionalização da carreira e do modus operandi da subida hierárquica. Na seção seguinte, apresento o tempo de duração de carreira conforme as respectivas hierarquias e como se desenham o acumulado médio de passagens, com especial atenção tanto às nomeações aos cargos de confiança ocupados na Sere, quanto em passagens por unidades diplomáticas no exterior, em instituições nacionais e internacionais, que ocupam todas as passagens possíveis da elite ministerial ativa no ano de atualização do banco.

\section{Referencial teórico}

O Itamaraty passou por complexos desenvolvimentos institucionais ao longo de sua história (CASTRO; CASTRO, 2009), sendo influenciado e simultaneamente impactando mudanças nos processos de profissionalização do serviço público nacional (ABRUcio et al. 2010). A criação do Instituto Rio Branco em 1945 (IRBr) tem importante papel nesse sentido e, no marco da transição democrática, o $\mathrm{IRBr}$ passa a ser um eixo fundamental da profissionalização do Itamaraty (CHEIBUB, 1985, 1989). Isto é, o papel do instituto na seleção, via concurso público, e formação dos quadros diplomáticos foi desenvolvendo-se e aperfeiçoando-se no tempo, aspecto que consolidou a monopolização e controle qualitativo do MRE sobre seus quadros. Esse processo é descrito na literatura como uma espécie de path dependence, que inseriu o ministério em um percurso crescentemente weberiano, burocrático e racional (CHEIBUB, 1985, 1989). Essa profissionalização incremental do Itamaraty, também fora entendida como relativamente afastada - portanto "insulada" - de demandas particularistas ou partidárias (GEDDES, 1994; SCHNEIDER, 1994).

Em teoria, com uma carreira profissional e salários adequados às funções exercidas, burocratas pertencentes a burocracias análogas ao tipo weberiano poderiam atuar imparcialmente frente às dinâmicas políticas e partidárias dos líderes governamentais, fazendo desse burocrata leal ao império da lei (rule of law), porém sobrecarregado por procedimentos, regras e documentação (WISE, 2004). No período alcançado pelo artigo, o Itamaraty se manteve como o ministério civil mais fechado dentro do Poder Executivo federal (LoureIRo; ABRUCIO, 1999; BERSH et al. 2016), tendo restringido e sendo bastante restritivo quanto às nomeações laterais para seus cargos de confiança, ou seja, possuindo a quase totalidade dos cargos comissionados no ministério direcionados para seus próprios servidores 
de carreira (LOPEZ, 2015). Há também uma baixíssima filiação partidária entre os quadros da elite corrente do ministério, verificada pelas informações disponíveis ${ }^{1}$, aspecto que está em consonância com outros achados que mostram o MRE com poucos principals partidários, o que lhe garante alta capacidade e autonomia (BERSCH et al. 2017).

Cabe salientar que assumir tais características weberianas também serve a propósitos estratégicos que, simultaneamente, limitam e legitimam a ação política dos atores que controlam a burocracia, mas não possuem mandatos eletivos (HUBER, 2007). Soma-se que burocratas tanto sofrem múltiplas pressões no desempenho de suas atividades, quanto possuem preferências sobre seus objetivos e interesses. Entre esses elementos, existem regras informais que ditam o jogo interno das instituições (CROZIER, 1963); processos de negociações e barganhas para dirimir os conflitos entre os atores (CYERT; MARCH 1963), ao que se incluem rivalidades e egoísmos competitivos (WILSON, 1989); há aqueles que priorizam promoções na carreira e/ou maior salário (TULLOCK, 1964; DowNS, 1967); e os que se aproximam de líderes eleitos para garantir espaço na tomada de decisão da elite ministerial (ABERBACH et al. 1981); outros almejam mais influência na política pública e/ou maior orçamento para a burocracia que pertencem (NISKANEN 1971); ou querem mais poder, prestígio, funcionários a sua disposição, ou escritórios, funções e/ou remoções para localidades importantes (DUNLEAVY, 1991) etc. Isto é, de um lado, o Estado não é um bloco uniforme nas burocracias e nos atores que o compõe, e, de outro, e por conta da diversidade de institucionalização de seus subsistemas, com variadas capacidades, autonomias e limitações, os burocratas estão longe de serem puramente neutros (BENDIX, 1945; DARGENT, 2014; WISE, 2014).

Como fora citado na introdução, o MRE contemporâneo é resultado de uma maior organização administrativa e estrutura institucional mais robusta, ao que se inclui a evolução de organograma do MRE (SILVA et al. 2010) e a estruturação progressiva da carreira diplomática. Nesse processo e, mais recentemente, com as gestões presidenciais de FHC e Lula, em paralelo ao destaque desses presidentes na condução da política externa (CASON; POWER, 2009), ambos implantaram significativos avanços na profissionalização da carreira. Entre essas alterações, podemos citar: a apropriação do ingressante aprovado no concurso no quadro diplomático e sua adequação salarial (MOURA, 2007); transparência de critérios e conteúdo somadas à divulgação pública de material para o concurso (FARIA et

\footnotetext{
${ }^{1}$ Cruzando os dados do anuário com os de filiações partidárias fornecidos por Mingardi (2018), pode-se verificar três filiações entre segundos ministros, sendo: um pelo PDT (com filiação em 2013); um filiado do DEM (aderindo ao partido em 1997), que transitou para o PSDB (em 2005) e para o PSD (em 2015); e um filiado do PT (com filiação datada em 2012). Entre os embaixadores, encontramos um embaixador filiado ao PT (em 2007) que transitou para o PSDB (em 2011), depois para o PSD (em 2013), e atualmente se encontra no PR (em 2016).
} 
al., 2013; AMADO, 2013); programa de ações afirmativas para afrodescendentes e temáticas de equiparação de gênero (BALBINO, 2011); além de significativa ampliação de vagas. Todavia e a despeito dos avanços institucionais, o perfil social de seus quadros contemporâneos e os padrões de promoção de sua elite diplomática são marcados mais por manutenções do que por mudanças, quando comparados aos achados de outrora (LIMA; OLIVEIRA, 2018; CHEIBUB, 1989).

Em relação à progressão na carreira, desde 1996, uma vez que o indivíduo é aprovado no exigente concurso de Admissão à Carreira Diplomática (Cacd), ingressa automaticamente no escalão inicial da carreira, de terceiro secretário, e passa a frequentar o IRBr por dois anos. No MRE, o sistema de promoção ocorre semestralmente através de um complexo sistema que combina antiguidade e méritos, predominando o merecimento a partir da segunda ascensão funcional ${ }^{2}$. Para angariar promoções faz-se necessário possuir determinado tempo mínimo de carreira, a depender da camada hierárquica em que o diplomata se encontra, concluir cursos avançados no IRBr, além de cumprir períodos no exterior, contabilizados de maneira distinta, a depender da localidade do posto.

Para cada promoção, são avaliados se o diplomata atingiu os critérios de elegibilidade através de votações verticais (de classes superiores para as inferiores) e horizontais (entre os pares hierárquicos), efetuadas por meio de uma Câmara de Avaliações e de uma Comissão de Promoções (BALBINO, 2011, 63-4), cujas instâncias são compostas por diplomatas da elite ministerial. Cabe ressaltar que burocratas do topo se diferenciam daqueles do médio e do baixo escalão, sobretudo porque os burocratas nos altos ranques são tomadores de decisão (OSTROM; OSTROM, 1971) e criam ou desenvolvem políticas públicas (ABERBACH et al. 1981), enquanto os demais as acompanham, são responsáveis por implementá-las, ou supervisionam sua implementação (HUBER, 2007). Tecnicamente, os burocratas dos níveis mais baixos são puramente subordinados, pois recebem ordens exclusivamente, já os do médio escalão recebem e dão ordens, e aqueles do topo dão mais ordens do que as recebem (HUBER, 2007).

Esses aspectos também servem de justificativa para a escolha da elite diplomática como objeto de estudo. Os desenhos das trajetórias, mesmo que de maneira exploratória e descritiva, dos atores que tiveram sucesso ao alcançarem os altos escalões, podemos avançar na compreensão dos aspectos inerentes a carreira, que envolvem conjuntamente as relações entre burocratas e burocracias, entre interesses individuais e coletivos, entre a instituição e seus processos internos

\footnotetext{
${ }^{2}$ As regras de promoção estão disponíveis no link do sindicato de servidores do Itamaraty: www.sinditamaraty. org.br/anexos/-01_QUADRO\%20COMPARATIVO\%20REGRAS\%20DE\%20PROMOCAO\%20NO\%20SERVICO\%20 EXTERIOR\%2OBRASILEIRO\%20-\%20FINAL.doc (link estável em 13 de junho de 2017)
} 
e externos, que resultam de dinâmicas políticas. Nesse aspecto, analisaremos toda a trajetória de ambos os estratos da elite, tal qual se nota nos Quadros abaixo.

Quadro 1 - Trajetória até segundo ministro, segundo degrau mais alto da carreira

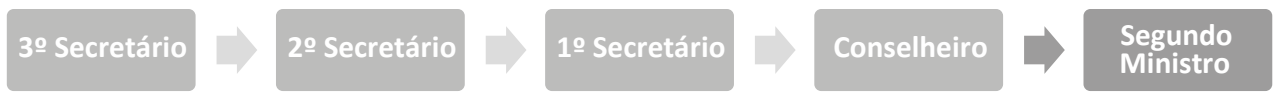

Nota: elaboração própria.

Quadro 2 - Trajetória até embaixador, degrau mais alto da carreira

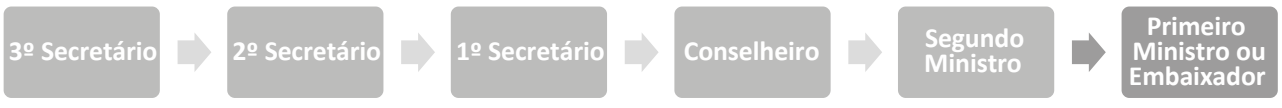

Nota: elaboração própria.

Na próxima seção, desenho essas trajetórias, e nas seções seguintes aplico coortes e divisões às categorias de interesse sugeridas, para posteriormente cruzálas com o tempo total de carreira.

\section{Método e discussão dos resultados}

Ao observar as hierarquias do topo ministerial, a análise direciona-se a ambos os grupos da elite diplomática: os segundos ministros $(N=235)$ e os embaixadores ( $N=186)$. O banco de dados utilizado e construído pelo autor tem como fonte principal o anuário do pessoal do MRE, diplomatas 2010, em que constam os dados dos currículos de todos os diplomatas ativos nesse ano no ministério, e os cargos comissionados, DAS, foram cedidos por Lopez (2015).

Faz-se fundamental ressaltar que as trajetórias da elite são analisadas desde o ingresso até o último dado de atualização do banco, estendendo-se por toda trajetória de cada indivíduo. Isso implica que as informações desenhadas vão desde o ano de entrada na carreira que compõe as chamadas turmas de formação diplomática no Instituto Rio Branco (IRBr) até o ano de 2010. Antes de avançar por entre esse intervalo, didaticamente apresento no próximo gráfico o padrão de evolução das promoções da elite diplomática, tal como exemplificados nos Quadros 1 e 2. No diagrama de caixas e bigodes (boxplot) abaixo, ilustra-se no passar do tempo, ano a ano e no decorrer das décadas o trajeto dos dois grupos da elite ao longo de sua subida hierárquica, desde o acesso (Turma IRBr) até o degrau de entrada nos escalões do topo. 
Gráfico 1 - Boxplot das promoções hierárquicas da elite diplomática ao longo do tempo

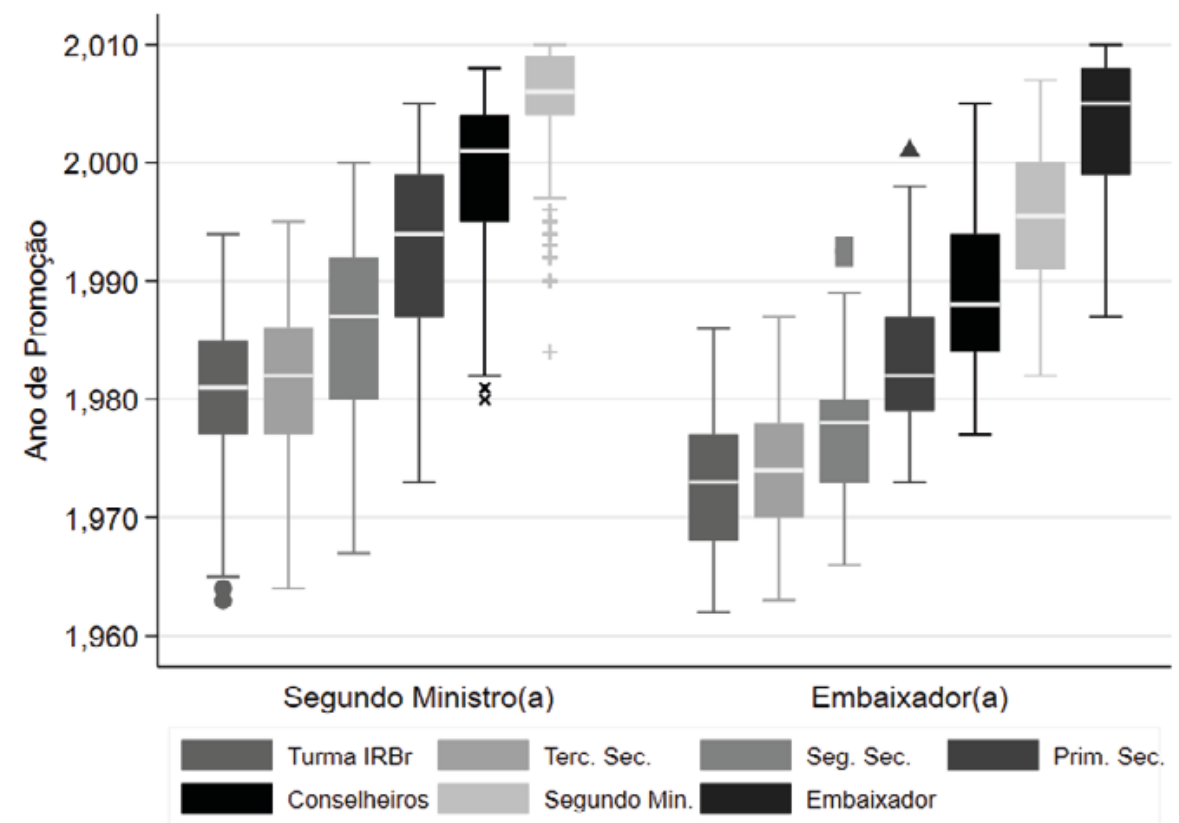

Fonte: anuário do pessoal diplomatas 2010, elaboração própria.

Notamos, para as caixas dos segundos ministros, que a turma do IRBr se concentra por volta dos anos 1980, e a chegada ao segundo mais alto escalão da carreira se dá em finais da década de 2000 - com valores extremos de atores que acessaram a posição principalmente ao longo dos anos 1990. Já para os embaixadores, a entrada na turma do IRBr ocorre nos finais dos anos 1960 e no decorrer da década de 1970, enquanto a maioria alcança o topo da carreira em finais e mais ou menos na década de 2000 - ao contrário dos segundos ministros e, ainda que a extensão do bigode se estenda para baixo, com promoções até os finais dos anos 1980', não observamos valores extremos para os embaixadores.

Se o Gráfico anterior desenhou os momentos de acesso, degrau a degrau desde a entrada até o acesso a elite diplomática no tempo, vejamos agora como se comportam os tempos totais de carreira, que compõem os períodos a serem analisados. No Gráfico a seguir, observam-se os tempos médios das trajetórias totais da elite diplomática: na parte superior temos os diagramas de caixas e bigodes (boxplots), e abaixo, as funções de densidade de probabilidade - o Stata faz o cálculo com base na densidade de kernel (kdensity) - com as respectivas médias tracejadas verticalmente - dos segundos ministros à esquerda, e dos embaixadores à direita -, em anos. 
Gráfico 1 - Boxplot, kdensity e média (tracejado vertical), dos tempos de carreira da elite diplomática, em anos

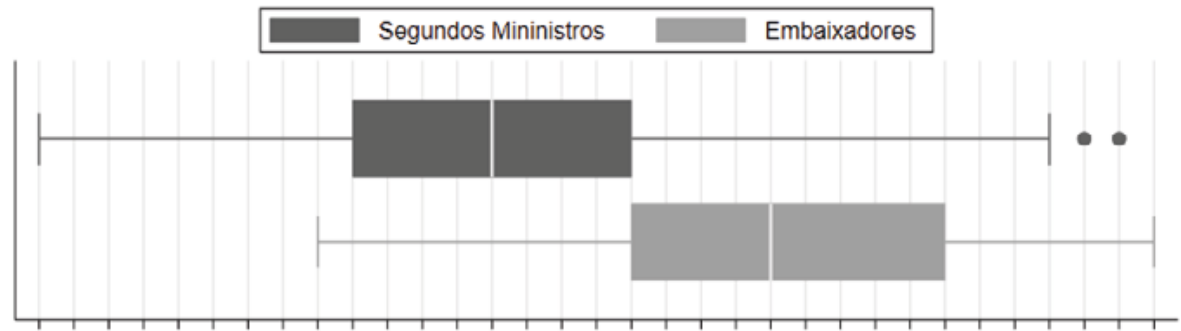

161718192021222324252627282930313233343536373839404142434445464748

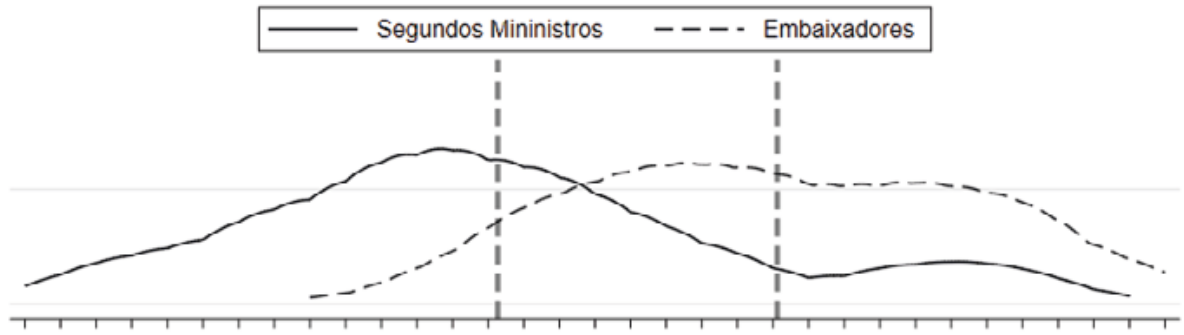

161718192021222324252627282930313233343536373839404142434445464748

Tempo de carreira (anos)

Fonte: anuário do pessoal diplomatas 2010, elaboração própria.

Para os altos escalões do ministério, relata-se que as medianas estão muito próximas de suas médias: para segundos ministros a mediana está em 29 anos e a média, em 29,27 anos, com desvio padrão de 6,76 anos, e, para os embaixadores, a mediana está em 37 anos, e a média, em 37,11 anos, com desvio padrão de 5,47 anos. Como a caixa sugere a concentração de $50 \%$ dos valores, nota-se que para os segundos ministros o intervalo interquartil está entre 24 e 33 anos - com alguns valores extremos -, ao passo que para embaixadores observamos um intervalo que vai de 33 até 42 anos de carreira analisados.

Para compreender os exercícios e gráficos efetuados no artigo é fundamental reiterar que a estrutura básica do MRE compreende a Secretaria de Estado das Relações Exteriores (Sere), que se constitui no conjunto de unidades burocráticas presentes no Brasil - em sua maioria concentradas no Itamaraty em Brasília, mas também com escritórios de representação pelo país -, em que utilizo como proxy a nomeação para 
cargos de confiança DAS na Sere, e em repartições no exterior ${ }^{3}$, em que contabilizo as passagens por consulados, embaixadas e demais unidades diplomáticas no exterior. Paralelamente, também efetuo a contagem para trânsitos por instituições nacionais, exclusive e exógenas a Sere, e/ou organismos internacionais, totalizando todas as movimentações institucionais dos burocratas, desde o ingresso do ator até seu último registro da carreira no banco. À guisa de exemplo, os segundos ministros tiveram uma média de 7,35 passagens em suas trajetórias (com desvio-padrão de 2,70 e com mínimo de 2 e máximo de 16 passagens), enquanto os embaixadores tiveram quase 9 passagens em média (com desvio de 2,80 e com mínimo de 4 e máximo de 18 passagens), ao longo de suas carreiras.

Para tanto, e a partir da contabilização dessas passagens, parametrizo-as de maneira bastante simples, considerando os totais individuais de passagens por instituições como $100 \%$ da trajetória de cada ator ativo e presente no anuário. Abaixo e para fins didáticos, efetuo o percentual médio para ambas as hierarquias da elite, conforme as subidas no decorrer dos degraus hierárquicos. Para oferecer didaticamente um exemplo, se um segundo ministro hipoteticamente teve um total de 5 passagens institucionais em toda sua trajetória, sendo uma para cada degrau de sua subida na carreira, desde terceiro secretário até segundo ministro, esse ator teria $20 \%$ de distribuição da frequência de passagens para cada ranque. Este é um exercício importante pois as descrições que serão efetuadas posteriormente levam igualmente em consideração essa mesma lógica, ainda que efetuados outros coortes e segmentações que não necessariamente hierárquicos. Antes de entrarmos nessas outras divisões, note como se distribui as trajetórias médias das passagens institucionais - externas à Sere - ao longo de suas carreiras, distribuídas segundo a evolução dos atores até o topo do ministério.

\footnotetext{
${ }^{3}$ Conforme o Regimento Interno da Secretaria de Estado das Relações Exteriores, do título II, da Estrutura Regimental do Ministério das Relações Exteriores, sexto artigo, relata-se: “A estrutura básica do MRE compreende: I - A Secretaria de Estado das Relações Exteriores (SERE), conjunto de unidades do MRE no Brasil, que abrange: (a) órgãos de assistência direta e imediata ao Ministro de Estado; (b) órgão central de direção: Secretaria-Geral das Relações Exteriores (SG); (c) unidades descentralizadas; (d) órgão setorial: Secretaria de Controle Interno (CISET); órgãos de deliberação coletiva; e (f) entidade vinculada: Fundação Alexandre Gusmão (FUNAG). II - as Repartições no exterior, as quais abrangem: (a) Missões Diplomáticas Permanentes; (b) as Repartições Consulares; e (c) Unidades Específicas, destinadas a atividades administrativas, técnicas, culturais ou de gestão de recursos financeiros. $\S 1$ 으 As Missões Diplomáticas permanentes qualificam-se como Embaixadas, Delegações Permanentes e Missões junto a organismos internacionais, criadas por decreto, o qual fixa sua natureza e sede. $\S$ 2ㅇ As Repartições Consulares qualificam-se como Consulados-Gerais, Consulados, Vice-Consulados e Consulados Honorários. Os Consulados-Gerais, Consulados e Vice-Consulados são criados por Decreto que estabelece sua natureza e sede; a respectiva jurisdição é estabelecida por ato do Ministro de Estado. Os Consulados Honorários são instituídos em ato do Ministro de Estado, que lhes estabelece a sede e a jurisdição. § 3ㅇ As repartições ou escritórios específicos, destinados a atividades administrativas, técnicas ou culturais são instituídos em ato do Ministro de Estado, que Ihes estabelece a competência, a sede e a subordinação administrativa". Acesso em: http://www.itamaraty.gov.br/images/RISE.pdf (link estável em 13 de jun. de 2017).
} 


\section{Gráfico 3 - Trajetórias médias (\%), conforme os degraus hierárquicos}
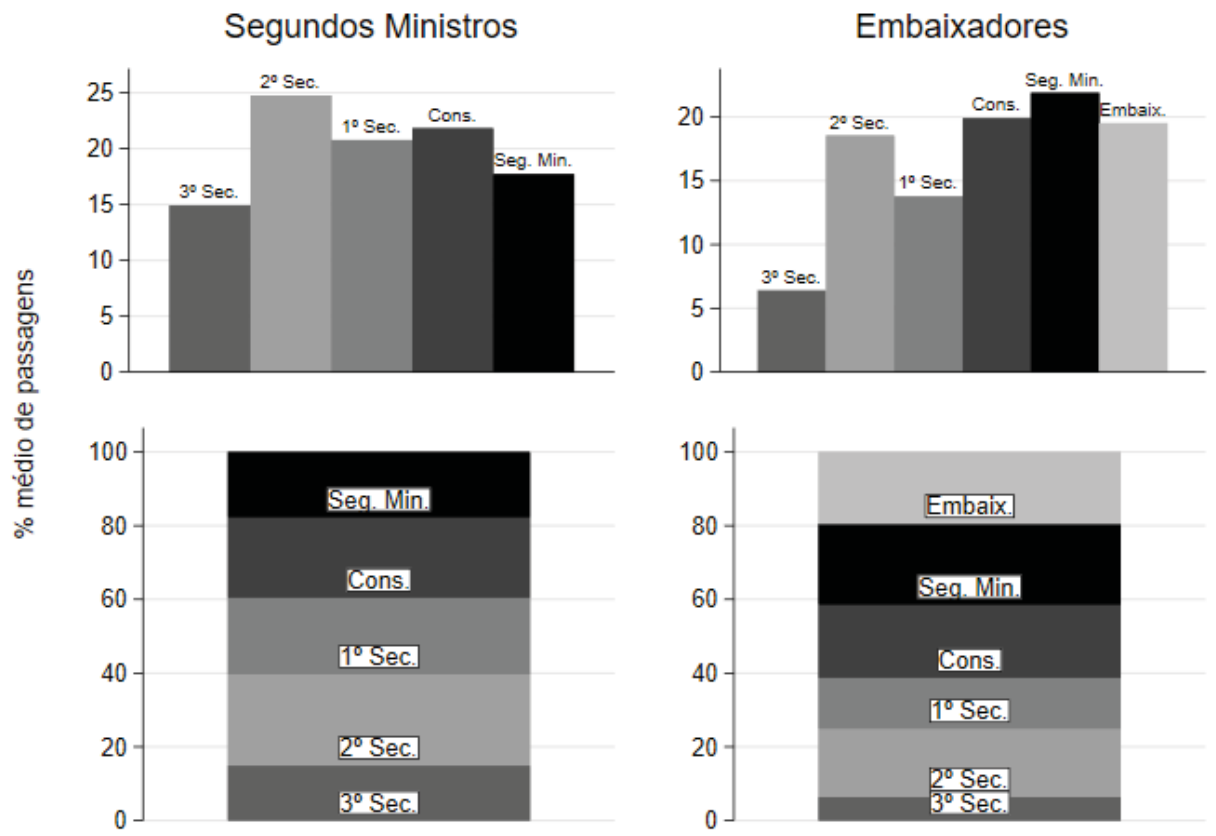

Fonte: anuário do pessoal diplomatas 2010, elaboração própria.

Um primeiro ponto que chama atenção em termos de semelhança entre os dois grupos da elite é a particular atividade de passagens para o degrau de segundos secretários, que concentram $25 \%$ e $20 \%$ das frequências, respectivamente. Para os segundos ministros o percentual de passagens para os escalões seguintes fica ao redor dos $20 \%$, enquanto para os embaixadores também se observa esse mesmo patamar concentrado nos ultimos tres degraus da carreira, sobretudo. Reitero que a ênfase do artigo recai sobre a frequência média da trajetória institucional dos atores e não há dessa maneira o controle sobre o tempo despendido nas categorias propostas - nesse quesito há um esforço de aproximação das frequências médias com os tempo médios de carreira, cruzando-as, mas sem um controle desagregado do tempo despendido nas respectivas categorias sugeridas.

Para visualizarmos em detalhes esses aspectos, temos duas subseções conseguintes. A primeira tem como objeto observar a dinâmica política interna à Sere, com informações relacionadas às nomeações dos cargos de confiança de direção e assessoramento (DAS). No caso, observaremos quais funções desempenham e como estão distribuídas essas nomeações por cada nível (do DAS-1 ao DAS-6) e quando tais indicações foram efetuadas. Na segunda e última 
subseção efetuaremos o exercício análogo ao que fizemos acima no Gráfico 3; no entanto, observando "por onde" os diplomatas transitaram com base em categorias institucionais de interesse, para então e ao final da subseção, as cruzarmos com os tempos médios de carreira.

\subsection{Dinâmicas internas na Sere: nomeações para cargos de confiança (DAS)}

Em termos gerais os cargos de direção e assessoramento (DAS), vulgo de cargos de confiança ou cargos comissionados DAS, referem-se a postos em ministérios e agências, em geral sob o controle do presidente ou do ministro, e se caracterizam como uma ferramenta capaz de incorporar pessoas de notório saber para o serviço público, construir equipes administrativas, beneficiar aliados, cooptar a oposição, e controlar poder econômico e político (D'ARAUJO, 2009, 178). As posições ocupadas pelos DAS, conjuntamente ao presidente, os ministros, e os cargos de natureza especial ou "NES" (postos logo hierarquicamente abaixo dos ministros e informalmente denominados de "vice-ministros"), representam a elite do Poder Executivo nacional. Seis hierarquias compõem os cargos DAS: os níveis 1, 2 e 3 são posições mais administrativas ou operacionais, ao passo que a elite, os níveis 4, 5 e 6, ao lado do NES, possuem funções na administração direta e política (DE BONIS; PACHECO,2010) - com poder decisório relativo e crescente, relacionados também e proporcionalmente aos salários ou comissões recebidas pelos respectivos escalões (LOPEZ et al. 2015; BERSH et al. 2017).

Descrever as nomeações aos cargos de confiança é fundamental, portanto, dado que se oferecem indícios da movimentação política, por meio da distribuição de postos administrativos e/ou políticos chave, dentro da Secretaria de Estado. No Quadro a seguir, podemos verificar as posições atribuídas aos níveis dos cargos de confiança em âmbito geral, e, também, os mais especificamente relacionados aos cargos DAS do MRE, inseridas as funções entre parênteses. 
Quadro 3 - Quadro das funções dos cargos de confiança DAS-1 ao DAS-6 no MRE

\begin{tabular}{|c|c|c|}
\hline \multicolumn{2}{|r|}{ DAS } & Cargo(s) \\
\hline \multicolumn{2}{|r|}{ NES } & Secretário Geral \\
\hline \multirow[t]{2}{*}{$\begin{array}{l}\text { DAS } \\
6\end{array}$} & 101.6 & $\begin{array}{l}\text { Secretário de órgãos finalísticos, Dirigente de Autarquias e Fundações, } \\
\text { Subsecretários de órgãos da Presidência da República (Subsecretários } \\
\text { Gerais e Diretor do Instituto Rio Branco) }\end{array}$ \\
\hline & 102.6 & Assessor Especial \\
\hline \multirow[t]{2}{*}{$\begin{array}{l}\text { DAS } \\
5\end{array}$} & 101.5 & $\begin{array}{l}\text { Chefe de Gabinete, Diretor de Departamento, Consultor Jurídico, } \\
\text { Secretário de Controle Interno, Subsecretário de Planejamento, } \\
\text { Orçamento e Direção (Secretario da Secretaria de Planejamento } \\
\text { Diplomático, Inspetor Geral, Corregedor Geral e Chefe de Cerimonial) }\end{array}$ \\
\hline & 102.5 & Assessor Especial (Gabinete do Ministro e Secretaria Geral) \\
\hline \multirow[t]{2}{*}{$\begin{array}{l}\text { DAS } \\
4\end{array}$} & 101.4 & $\begin{array}{l}\text { Coordenador Geral (Subchefe do Gabinete do Ministro, Chefe } \\
\text { da Assessoria de Imprensa do Gabinete, Chefe de Gabinete das } \\
\text { Subsecretarias, Diretor Geral Adjunto do IRBr, Subchefe de Cerimonial } \\
\text { e Chefe dos Escritórios de Representação) }\end{array}$ \\
\hline & 102.4 & $\begin{array}{l}\text { Assessor (Gabinete do Ministro, Secretaria Geral, e Agência Brasileira } \\
\text { de Cooperação) }\end{array}$ \\
\hline \multirow{2}{*}{$\begin{array}{l}\text { DAS } \\
3\end{array}$} & 101.3 & $\begin{array}{l}\text { Coordenador (em subsecretarias, assessorias, departamentos, } \\
\text { divisões etc.) }\end{array}$ \\
\hline & 102.3 & Assessor técnico \\
\hline \multirow{2}{*}{$\begin{array}{l}\text { DAS } \\
2\end{array}$} & 101.2 & $\begin{array}{l}\text { Chefe de Divisão (Gerente e Chefe de Setor; Chefe de Secretaria } \\
\text { Acadêmica e Administrativa do IRBr) }\end{array}$ \\
\hline & 102.2 & Assistente \\
\hline \multirow{2}{*}{$\begin{array}{l}\text { DAS } \\
1\end{array}$} & 101.1 & Chefe de seção, assistência intermediária \\
\hline & 102.1 & Assistente técnico \\
\hline
\end{tabular}

Nota: O Quadro foi extraído e adaptado de Cavalcante e Lotta $\left(2015\right.$, p. 16), que tem como fonte o art. $4^{\circ}$ do Decreto $n^{\circ} 4.567$, de $1^{\circ}$ de janeiro de 2003. As informações entre parênteses sumarizam a estrutura regimental e o quadro demonstrativo dos cargos em comissão e das funções gratificadas do Ministério das Relações Exteriores, apresentado pelo Decreto no 7.557, de 26 de agosto de 2011.

Cabe destacar que o Itamaraty lidera a proporção de cargos de confiança direcionados a atores pertencentes a sua própria carreira, ou seja, apresenta a taxa mais elevada dos DAS direcionados aos seus próprios servidores, quando comparado a outros ministérios nacionais, com 90,5\% das nomeações DAS destinadas aos que fazem carreira no MRE (LOPEZ, 2015). A seguir, vê-se em quais dos níveis de DAS estão concentradas tais nomeações na elite do ministério, situadas na parte de cima do Gráfico, enquanto na parcela abaixo o diagrama de caixa e bigodes (boxplot) descreve o ano dessas indicações, em comparação ao evento da promoção à elite. 
Gráfico 4 - Nomeações para cargos de confiança (\%) por nível de DAS (acima), e boxplot para o momento das indicações (abaixo)
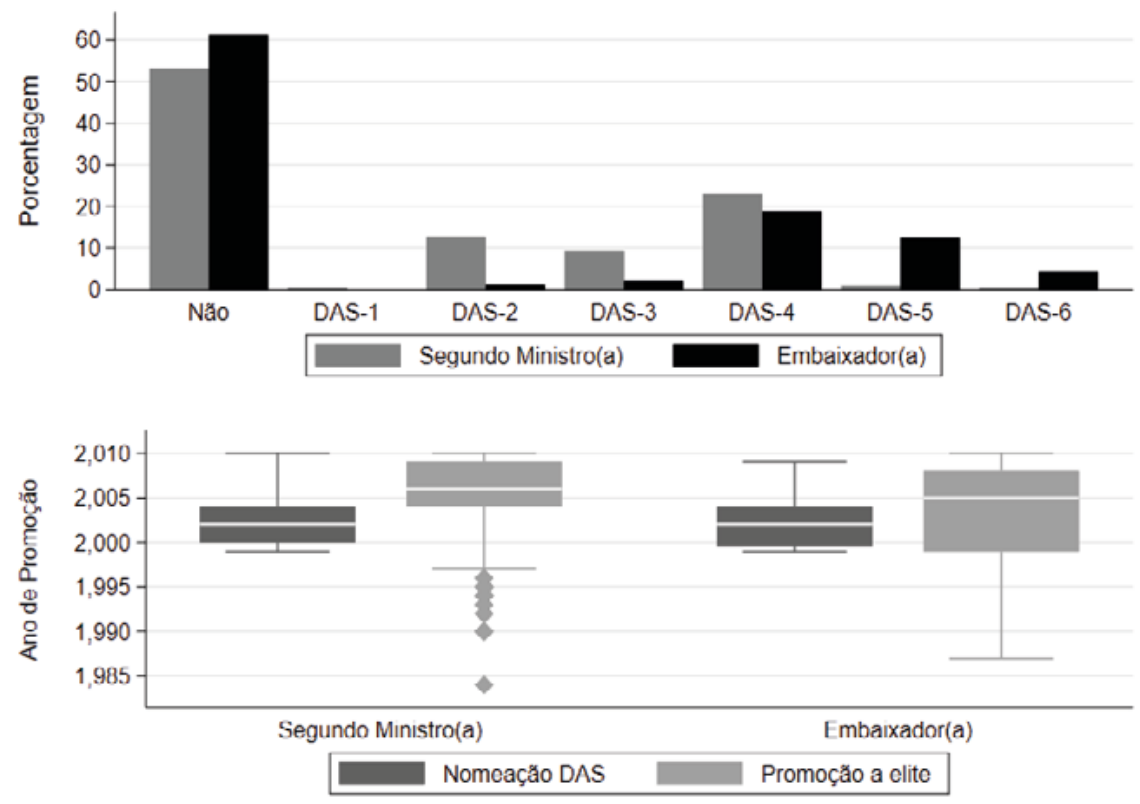

Fonte: Lopez (2015) para os DAS e anuário do pessoal diplomatas 2010, elaboração própria.

Para ambas as hierarquias, nota-se que menos da metade dos atores tiveram alguma nomeação para um cargo de confiança DAS na Sere, ao longo de suas carreiras, aspecto que ilustra a alta seletividade desses postos dentro da própria elite burocrática (correspondentes aos dados disponíveis das nomeações, desde 1999). Em relação ao gráfico de barras, observa-se que é o DAS-4 o nível que possui o maior percentual de nomeação, próximo da casa dos $20 \%$, para os dois estratos elite. Esse achado, de um lado, está em sintonia com as regras institucionais do MRE, em que para se acessar o posto de embaixador pela via de merecimento (e não antiguidade), por exemplo, tem-se como critério a necessidade de "tempo de função de chefia nível igual ou superior ao DAS-4 ou no exterior" (Lei $n=11.440 / 2006$, do MRE). Nesse sentido, e de outro lado, ser indicado para algum cargo de confiança apresentou diminuição do tempo de ascensão a segundo ministro, em um ano e meio em média, quando comparados aos que não foram nomeados para nenhum DAS, ceteris paribus (LIMA; OLIVEIRA, 2018). Paralela e descritivamente, também se observa que os cargos relativos ao DAS-5 e DAS-6, na casa dos $10 \%$, e próximos dos $5 \%$ para os embaixadores, mostram que as posições de chefia no Itamaraty são quase que exclusivamente endereçadas aos atores do topo da carreira, com ínfima indicação desses postos para segundos ministros. 
3.2. Trajetórias externas a Sere: instituições nacionais, organismos internacionais, e postos diplomáticos no exterior

Visto a dinâmica dos cargos de confiança DAS que operam dentro da Sere, aqui avançamos na descrição de como são as trajetórias para fora da Secretaria de Estado. Isto é, considere o exercício efetuado anteriormente, que considera as passagens totais de cada diplomata como $100 \%$ da trajetória registrada, no entanto, e nesse momento, os percursos de carreira serão divididos com base em três agrupamentos. Para tanto, proponho três macro categorias institucionais: (i) as instituições nacionais envolvem passagens pelas demais burocracias do país (exclusive a Sere), em qualquer um dos três poderes ou níveis federativos; (ii) os organismos internacionais contabilizam participações em missões diplomáticas, representações e/ou delegações permanentes em instituições internacionais formais ou informais; e por fim, (iii) os postos diplomáticos têm a frequência dos atores nas missões diplomáticas em postos fixados no exterior - vulgo embaixadas, consulados e missões permanentes -, além de postos específicos destinados a atividades administrativas, técnicas, culturais ou gestão de recursos financeiros, também sediados no exterior. Mais adiante detalharemos os porquês dessas categorias e justificaremos segmentações outras; antes, verifique como estão distribuídas as trajetórias da elite.

\section{Gráfico 5 - Trajetórias médias (\%) e boxplot, conforme as categorias institucionais}

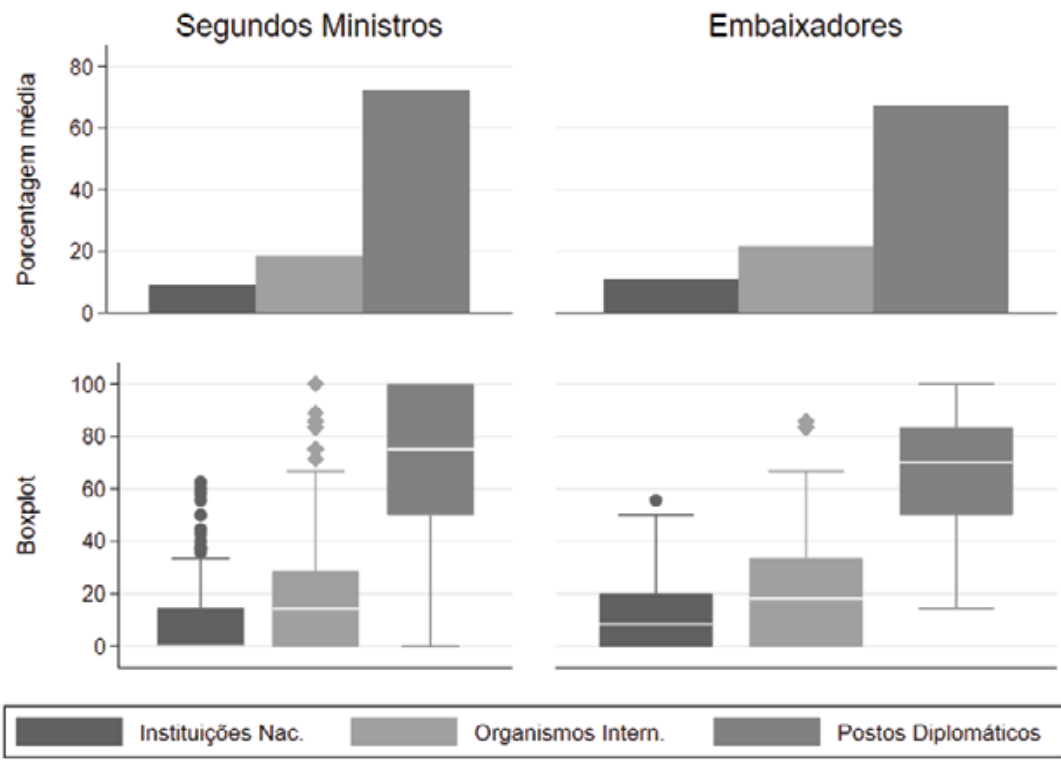

Fonte: anuário do pessoal diplomatas 2010, elaboração própria. 
Comparativamente, os dois escalões da elite apresentam um padrão relativamente similar de trajetórias médias. Isto é, se olharmos primeiramente para os gráficos de barras na parte superior do gráfico, as carreiras estão concentradas nos postos diplomáticos, com $70 \%$ e $60 \%$ da frequência média para segundos ministros e embaixadores, respectivamente. Para ambas as hierarquias, os organismos internacionais encontram-se próximos da casa dos $20 \%$, e, para as instituições nacionais, ao redor de $10 \%$. Em relação a essas duas últimas categorias institucionais, o que salta aos olhos são os vários valores desviantes para os segundos ministros, com múltiplos outliers para as instituições nacionais, e com um extenso bigode e muitos casos desviantes também para os organismos internacionais.

Propõe-se, para as demais análises descritivas a seguir, a desagregação dessas macrocategorias propostas, com base na literatura especializada. Comecemos pelo grupo das instituições nacionais. A Constituição de 1988 não modificou profundamente as atribuições da política externa nacional (Sanchez et al. 2006), mantendo-a concentrada no âmbito do Poder Executivo, mais especificamente na Presidência da República (PR), ao passo que o MRE continua como instituição de apoio aos brasileiros no exterior e de assessoramento à $P R$ para temas internacionais. Nesse aspecto, o papel de protagonismo institucional do MRE depende da omissão, autorização ou delegação da Presidência para suas atividades em política externa (LIMA, 2000). Além do patrocínio político ao Itamaraty e outros serviços que os diplomatas prestam de praxe à $\mathrm{PR}$, pode-se sugerir que o trânsito de diplomatas pela Presidência seria uma das inúmeras formas de se estabelecerem relações com o centro do sistema político. Desse modo, o trabalho propõe uma separação entre a PR das demais instituições e burocracias nacionais.

Para o grupo dos organismos internacionais, reforça-se que a Organização das Nações Unidas (ONU), principal organização política internacional (AMORIM NETO,, 2011, p. 129), constitui-se em fundamental interesse, histórico e presente para a política externa brasileira (AMORIM NETo, 2011; LIMA; HIRST, 2009). Entende-se que a ONU e seu extenso guarda-chuva institucional cumpram parte fundamental dos interesses nacionais da política externa multilateral, e, para tanto, separamos-la das demais organizações internacionais (Ols).

Por fim, o grupo dos postos diplomáticos foi dividido de acordo com classificação de postos diplomáticos no exterior, fornecida pelo MRE, compatível com a atualização das informações do anuário, em 2010, que se separam os consulados, embaixadas e demais postos específicos, em quatro classes: "A", 
"B", "C" e "D" ${ }^{4}$. Para exemplificar, os consulados e embaixadas pertencentes à classe " $A$ " estão localizados em: Barcelona, Berlim, Berna, Boston, Bruxelas, Buenos Aires, Chicago, Genebra5, Haia, Lisboa, Londres, Los Angeles, Madri, Miami, Milão, Nova York, Paris, Roma, São Francisco, Vaticano, Viena e, por último, porém não menos importante, Washington. Vejamos como se comporta o gráfico de barras anterior, agora desagregado nessas subcategorias, teoricamente sugeridas pela literatura.

\section{Gráfico 6 - Trajetórias médias (\%) com as subcategorias institucionais}
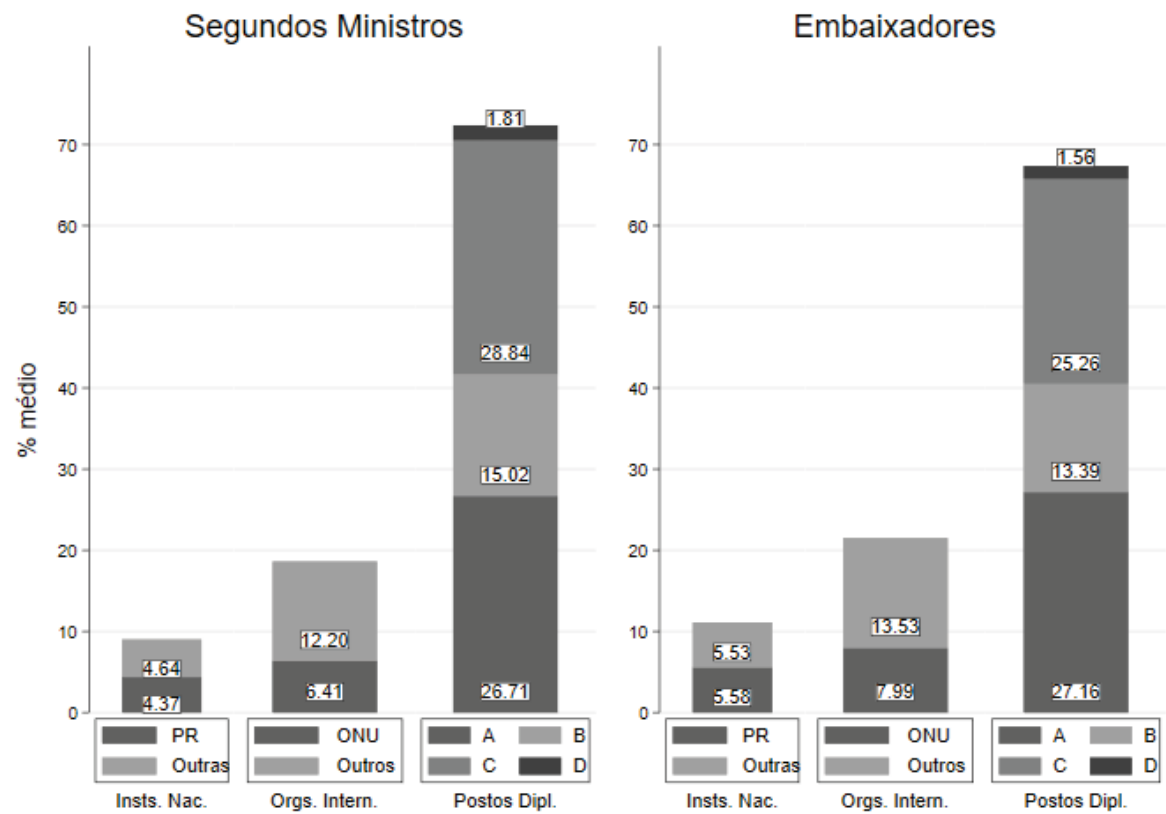

Fonte: anuário do pessoal diplomatas 2010, elaboração própria.

\footnotetext{
${ }^{4}$ Para a consulta dos postos diplomáticos pertencentes às demais classes, conforme a Portaria de no 534 , de 31 de agosto de 2010, acessar: http://www.asof.org.br/arquivos_site/c438b8f77d455975e82614f3cd786c68.pdf (link estável em 13 de junho de 2017). Os postos diplomáticos que constam com passagens no anuário de 2010 e não mais existem, foram classificados como "NA" e retirados da análise, mas seguem presentes no banco para consulta.

${ }^{5}$ A única exceção de missão diplomática com posto fixado no exterior, na classificação do MRE mas que entrou na categoria de organismo internacional, era a então chamada "Delegação Permanente em Genebra" nos currículos dos diplomatas no anuário de 2010. Nesse momento, em seu site oficial http://delbrasgen. itamaraty.gov.br , fora renomeada de "Missão Permanente do Brasil junto à Organização das Nações Unidas e Demais Organismos Internacionais em Genebra". Como o posto da missão diplomática em Genebra, era então classificado (vide nota de rodapé anterior) como Genebra-OMC e Genebra-Desarmamento, que cede apoio institucional direto e respectivamente a essas instituições na ONU, a "Delegação Permanente em Genebra" foi incluída na categoria ONU.
} 
Guardadas as devidas proporções, os padrões médios das trajetórias dos dois mais altos escalões são relativamente similares. De um lado, a Presidência da República mais ou menos se equipara às demais burocracias nacionais em frequência média, e, de outro, a ONU se mostra menos frequente quando comparada às demais organizações internacionais, em média. Para os postos diplomáticos, que concentram a maioria das trajetórias, os postos da classe " $A$ " e os da classe " $C$ " se destacam, com mais de $25 \%$ da carreira, em média e para ambos os ranques da elite.

Para a última etapa do artigo, cruzamos essas trajetórias institucionais desagregadas com os tempos de carreira dos atores. Ao efetuarmos esse exercício, é possível verificar a existência de padrões associativos entre as frequências de passagens institucionais com as trajetórias médias de tempo da elite burocrática. Para fins didáticos e comparativos, incluiremos também três linhas verticais, sendo com um desvio padrão para menos da média, a linha média do tempo de carreira, e um desvio padrão para mais da média, para ambos os grupos de elite - as análises se concentraram especificamente entre esses intervalos. Comecemos com as frequências de passagens por instituições nacionais e organismos internacionais.

\section{Gráfico 7 - Trajetórias médias (\%) e o tempo de carreira (em anos) para instituições nacionais e organizações internacionais}

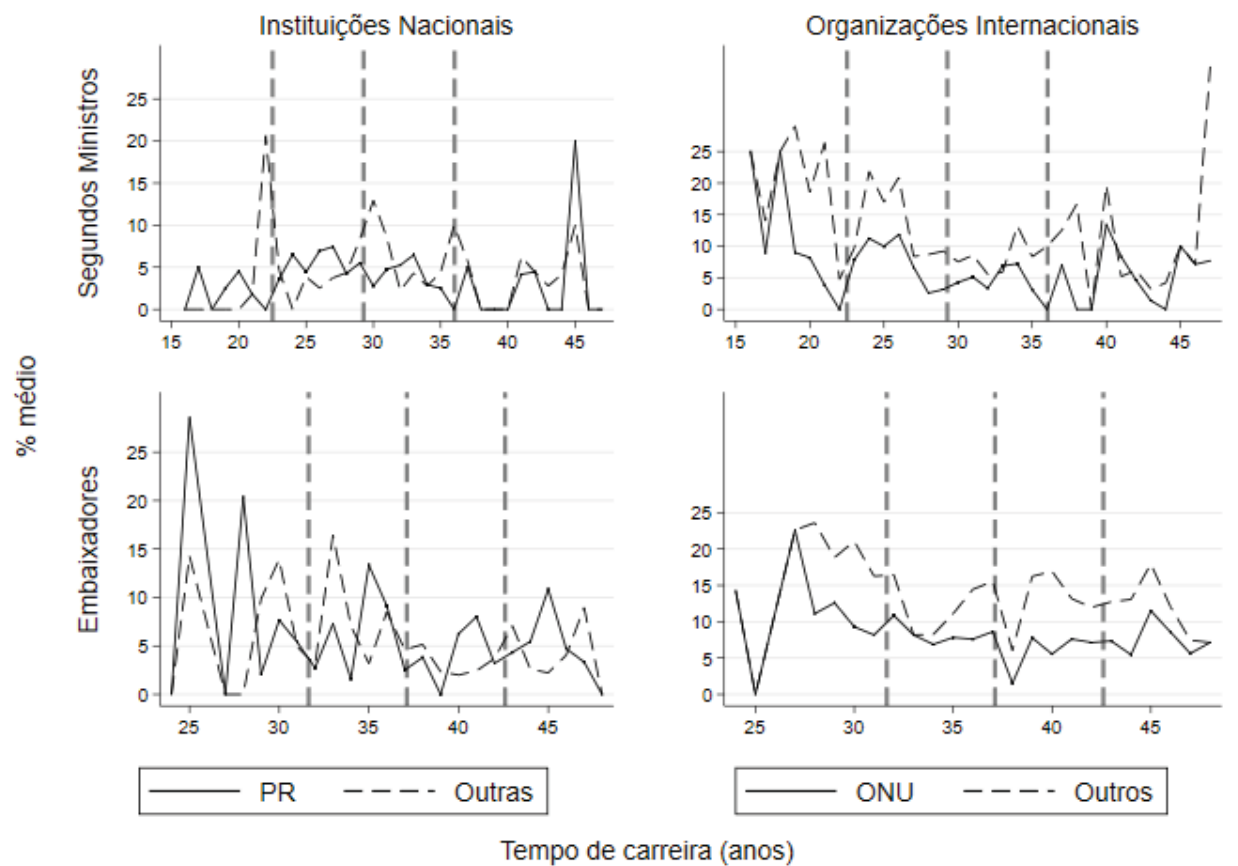

Fonte: anuário do pessoal diplomatas 2010, elaboração própria. 
Vimos no Gráfico 5 que as frequências médias de passagens por instituições nacionais apresentaram tanto um baixo percentual quanto possuem dados discrepantes, o que implica em parcimônia ao traçarmos essa associação média. A dispersão dos dados fica evidente para essa categoria, principalmente para além das linhas de desvio padrão. No entanto, e para segundos ministros e embaixadores, notam-se oscilações sistemáticas e revezamento entre as frequências médias de passagem pela Presidência e por outras burocracias nacionais, ao longo do tempo das trajetórias dos atores.

Para os organismos internacionais, ao que parece e à primeira vista, visualiza-se um padrão relativamente similar para as duas hierarquias do topo. A tendência sugerida pelos gráficos sugere apontar que as trajetórias por outros organismos internacionais superam a ONU, independentemente do tempo de carreira dos atores.

Por fim, e antes de desagregarmos os postos diplomáticos e as trajetórias médias dos atores, podemos verificá-los abaixo de maneira agregada. Dessa maneira, observe primeiramente a trajetória em unidades da chancelaria no exterior sem efetuarmos as divisões por classe.

\section{Gráfico 8 - Trajetórias médias (\%) por postos diplomáticos (agregados)}

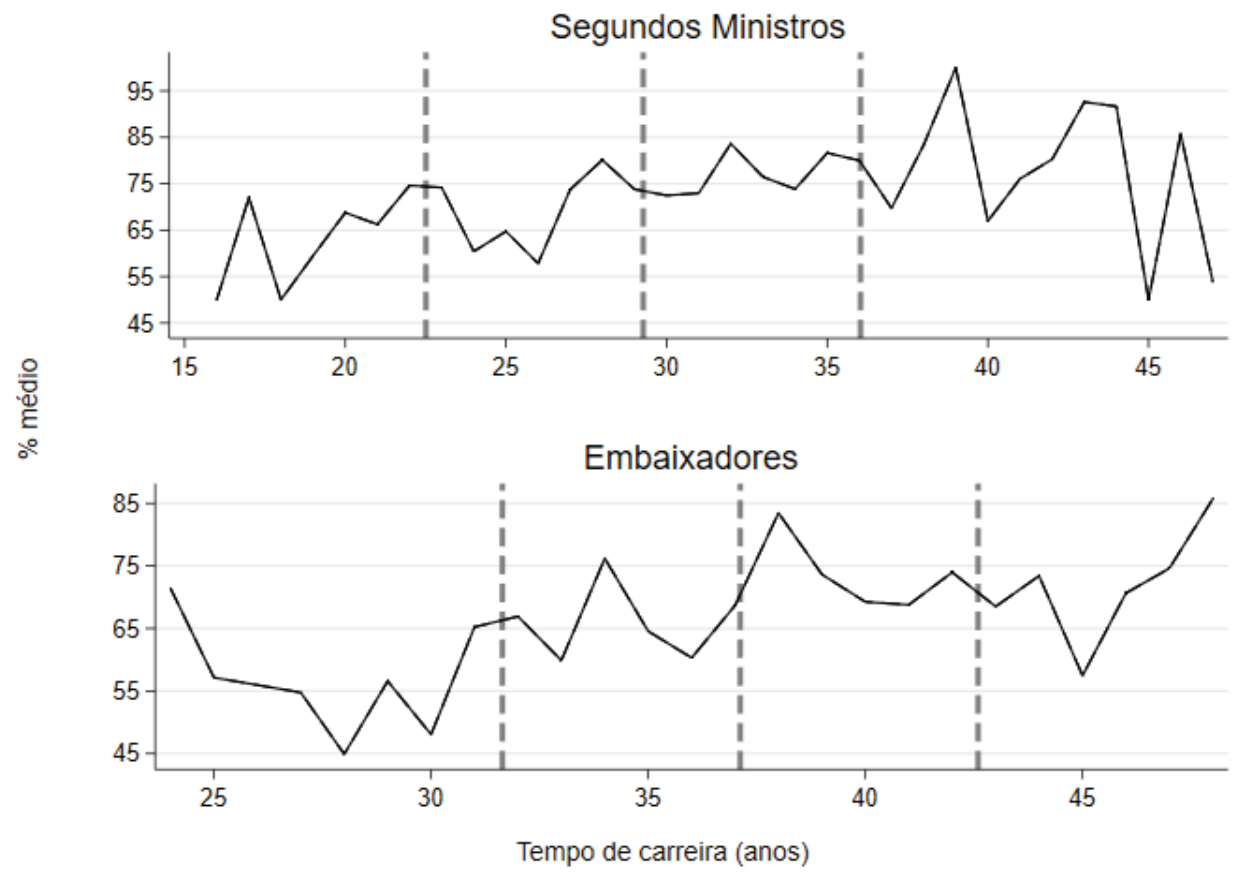

Fonte: anuário do pessoal diplomatas 2010, elaboração própria. 
Se olhamos com mais atenção e especialmente para a linha média e dentro dos desvios padrão, parece haver uma tendência crescente de passagens por postos diplomáticos conforme o aumento do tempo de carreira, aspecto que é bastante intuitivo. Entretanto, e como vimos anteriormente, as passagens por postos diplomáticos constituem tanto a maioria das frequências das trajetórias da elite, quanto existem diferenças nas distribuições e classes dos postos, classificados qualitativa e discricionariamente pelo ministério. Recordemos que se destacaram com as maiores frequências de passagens no Gráfico 3, os postos " $A$ " e " $C$ ". De maneira interessante, a maior quantidade de postos diplomáticos se concentram na classe " $C$ ", todavia, e de outro lado, é intuitivo afirmar que as maiores e mais estruturadas unidades no exterior se encontrem na classe " $A$ ", por serem as principais chancelarias na classificação ministerial e estarem no centro do sistema internacional e de interesse da política externa brasileira.

\section{Gráfico 9 - Unidades diplomáticas no exterior por classe (\%)}

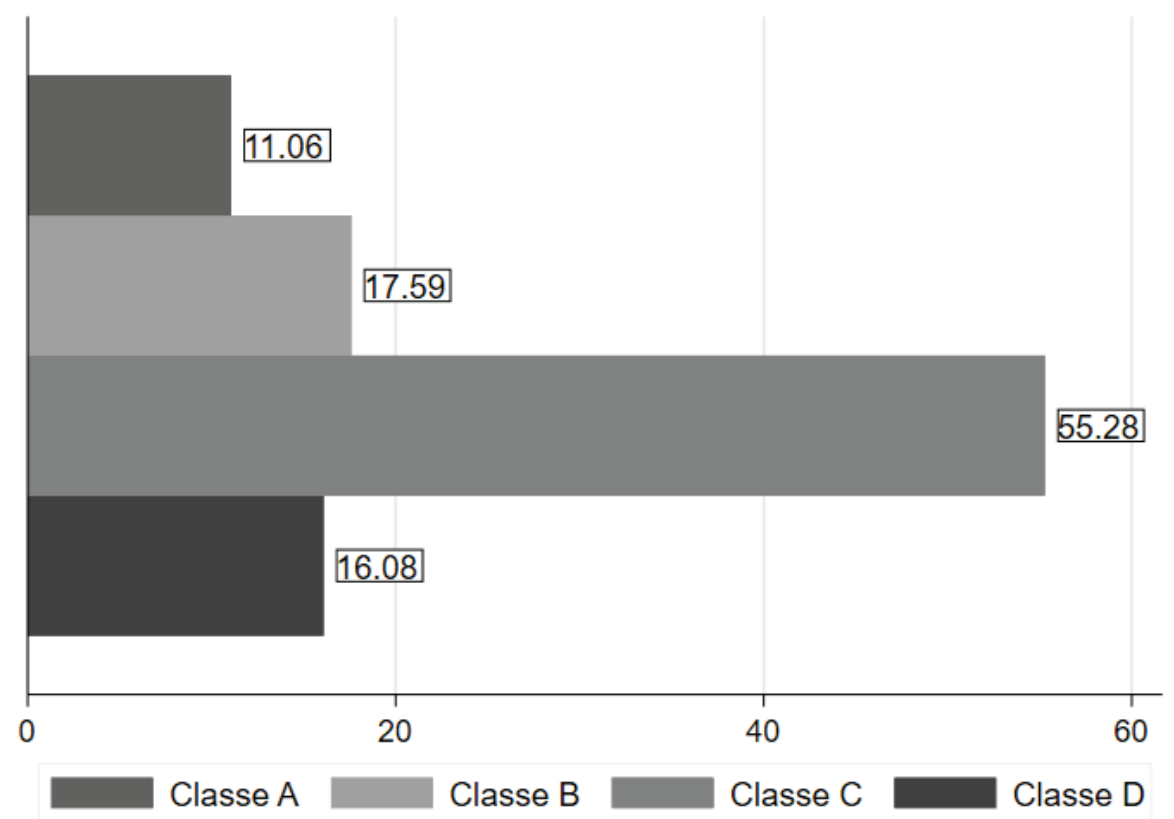

Fonte: Portaria do MRE no 534, de 31 de agosto de 2010, elaboração própria.

Adiciona-se o fato de existirem outras diferenças institucionais importantes, como a duplicação do tempo de permanência em postos " $\mathrm{C}$ ", e a multiplicação pelo triplo, na categoria "D", para fins de promoção instituídos na portaria próxima à atualização da data do banco (Portaria do MRE no 534, de 31 de agosto de 2010). Esse ponto é chave, pois, a despeito do incentivo institucional e da alta frequência 
relativa de passagem por postos " $C$ ", reitera-se que existe resistência por parte dos diplomatas da elite no trânsito por "postos menores e de sacrifício", assim chamados os pertencentes às classes " $C$ " e " $D$ ", principalmente aqueles postos sediados na África, conforme relatara uma embaixadora". Esse aspecto pode ser indicativo também do baixo percentual das trajetórias por postos da classe "D", conjuntamente ao fato de serem embaixadas e consulados recém-inaugurados na gestão Lula. Foi também verificado empiricamente que passagens por postos diplomáticos das classes " $\mathrm{B}$ " e " $\mathrm{C}$ " aumenta significativamente o tempo de promoção tanto para segundos ministros quanto para embaixadores, quando comparados àqueles que não passaram nenhuma vez por esses postos (LIMA; OLIVEIRA, 2018). Feitas essas considerações, observemos as passagens por postos de maneira desagregada, conforme as categorias de classificação do MRE.

\section{Gráfico 10 - Trajetórias médias (\%) por postos diplomáticos (desagregados)}

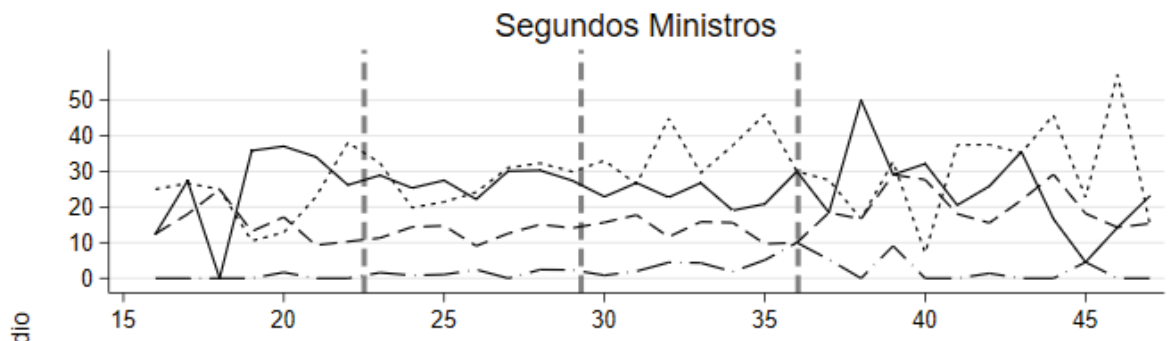

음

Embaixadores

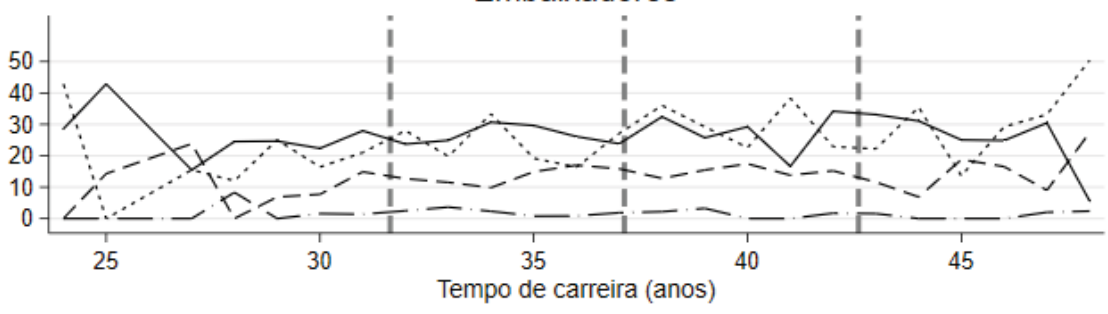

Classe A ---- Classe B

Classe C - Classe D

Fonte: anuário do pessoal diplomatas 2010, elaboração própria.

\footnotetext{
${ }^{6}$ Relata a embaixadora em Acra que: "De um modo geral, ainda na atual geração, os funcionários mais destacados da estrutura do Itamaraty nunca passaram por esses postos [C e D], sobretudo na África. A mensagem é de que a África, ou postos menores e de sacrifício, não podem estar no currículo daqueles que esperam fazer uma bela carreira na Chancelaria", continua a embaixadora que "Felizmente isso está mudando". Vide reportagem de agosto de 2012 da Folha de São Paulo, intitulada "Novos postos viram 'mico' no Itamaraty". Acesso (link estável em 13 de junho de 2017) em: http://www1.folha.uol.com.br/fsp/mundo/61438-novos-postos-viram-mico-noitamaraty.shtml
} 
Novamente, segundos ministros e embaixadores apresentam padrões similares de comportamento de trajetórias rumo à subida hierárquica, com particular destaque para os postos " $A$ " e " $C$ ". Descritivamente, e no intervalo abaixo da média, ambos os postos parecem revezar na liderança de maior frequência média, enquanto no intervalo acima da média do tempo de carreira os postos da classe " $C$ " se destacam mais sistematicamente.

\section{Considerações finais}

Com base em um banco de dados original, e considerando os percursos das trajetórias da elite, vimos que ambas as altas hierarquias da diplomacia nacional apresentam padrões médios similares em suas trajetórias. Nota-se que as nomeações aos cargos de confiança na Secretaria de Estado (Sere) estão mais concentradas para o nível intermediário de DAS-4, ao passo que os postos de alto comando político, de DAS-5 e DAS-6, ficam quase exclusivamente sob o comando de embaixadores.

Nas trajetórias exógenas à Sere, a elite diplomática mostrou baixo trânsito por instituições nacionais. A alta dispersão desses dados também aumenta a insegurança quanto a um padrão médio mais evidente, todavia, e para ambos os escalões superiores, a Presidência da República sugere dividir espaço equivalente em frequência de passagens com as demais burocracias nacionais. Já para as organizações internacionais, ainda que as frequências tampouco saltassem aos olhos, chama a atenção o fato de que outros organismos internacionais superam a ONU com maior concentração média em ambas as hierarquias e de modo sistemático, por diferentes tempos de carreira da elite.

Por fim, os postos diplomáticos apresentaram as trajetórias majoritárias dos altos escalões da burocracia diplomática. Novamente, observamos um padrão de comportamento similar entre segundos ministros e embaixadores que tiveram as mais altas frequências distribuídas entre os postos de classes " $A$ " $\mathrm{e}$ " $C$ ". Esse último nível parece estar à frente das frequências nos intervalos com um desvio padrão acima dos tempos médios, ao passo que no intervalo abaixo ambas essas classes sugerem se revezar nos comportamentos das trajetórias dos estratos da elite.

O artigo, ao optar por uma via descritiva e exploratória, levantou pontos importantes para avançarmos tanto na compreensão dos perfis de trajetórias de uma tradicional elite de Estado, quanto e igualmente no entendimento da relação entre as preferências e prioridades dos trânsitos institucionais que derivaram da relação entre burocratas e ministério, em um ambiente tradicionalmente burocrático e até então, politicamente fechado à interferências externas diretamente no ministério. 
As trajetórias institucionais, portanto, não dizem respeito pura e simplesmente à carreira dos diplomatas, mas também desenham relações mais amplas e complexas. Isso porque e para além dos percursos profissionais per se, existem estruturas e instrumentos institucionais que se relacionam à progressão e à movimentação mais ou menos discricionária dos atores, e da influência que a instituição exerce sobre eles, aspectos que nos oferecem pistas de como se estabelecem os relacionamentos políticos do ministério. Há, nesse sentido, relações políticas e de vias de mão dupla, entre a burocracia e seus servidores públicos de elite, que articulam preferências pessoais e coletivas, em dinâmicas próprias, em que operam e adequam a necessidade estrutural e institucional do próprio MRE e suas prioridades e motivações individuais. Ainda que o artigo não tenha avançado em profundidade a respeito dessas complexas nuances, a análise descritiva sugerida pela pesquisa abre uma importante e original agenda em que potencialmente se podem derivar desdobramentos e impactos das interações entre burocratas, carreira e política em ministérios nacionais, e seus possíveis impactos para a política pública oferecida.

\section{Referências bibliográficas}

Aberbach, Joel D.; Robert D. Putnam; Bert A. Rockman. Bureaucrats and politicians in Western democracies. Cambridge, Massachussets: Harvard University Press. 1981.

Abrucio, Fernando Luiz; Pedrotı, Paula; Pó, Marcos Vinicius. A formação da burocracia brasileira: a trajetória e o significado das reformas administrativas. In: Burocracia e Política no Brasil: dDesafios para a ordem democrática no século XXI. Rio de Janeiro: FGV, 2010, p. 27-72.

AMORIM Neto, Octavio.. De Dutra a Lula: a condução e os determinantes da política externa brasileira. $1^{\text {a }}$ ed., Rio de Janeiro: Elservier. 2011.

BALBINo, Viviane Rios. Diplomata, substantivo comum de dois gêneros: um estudo sobre a presença das mulheres na diplomacia brasileira. Brasília: Funag, 2011.

BENDIX, Reinhard. Bureaucracy and the problem of power. Public Administration Review, v. 5, n. 3, p. 194-209, 1945.

BerSCH, Katherine; PraçA, Sérgio; MATtheW, M. Taylor.. State capacity, bureaucratic politicization, and corruption in the brazilian state. Governance, v. 30, n. 1, p. 10524, 2016.

CASON, J. W.; T. J. Power.. "Presidentialization, pluralization, and the rollback of Itamaraty: explaining change in Brazilian foreign policy making in the Cardoso-Lula Era". International Political Science Review, v. 30, n. 2, p. 117-40, 2009.

CASTRO, Flávio Mendes de Oliveira; CASTRO, Francisco Mendes de Oliveira. . 18082008: Dois séculos de história da organização do Itamaraty. v. 2 (1979-2008). Brasília: Fundação Alexandre de Gusmão (Funag. 2009. 
CHeıbub, Zairo Borges. Diplomacia e construção institucional: o Itamaraty em uma perspectiva histórica. Dados, v. 28, n. 1, p. 113-31, 1985.

A carreira diplomática no Brasil: o processo de burocratização do Itamarati. Revista de Administração Pública, v. 23, n. 2, p. 97-128, 1989.

CrozIER, Michel. The bBureaucratic phenomenon. New Brunswick, N.J: Transaction Publishers. 1963.

CYERT, Richard M.; JAMES, G. March.. Behavioral theory of the firm. Cambridge, Massachusetts: Wiley-Blackwell. 1963.

DARGENT, Eduardo.. Technocracy and democracy in Latin America: the experts running government. New York: Cambridge University Press. 2014.

Downs, Anthony. Inside bureaucracy. Boston: Little Brown \& Company. 1967.

DUNLEAVY, Patrick. Democracy, bureaucracy \& public choice. London: Havester Wheatsheaf. 1991.

FARIA, Carlos Aurélio Pimenta de; DAWISSON, Belém Lopes; CASARÕES, Guilherme. Itamaraty on the move: institutional and political change in Brazilian foreign service under Lula da Silva's Presidency (2003-2010)". Bulletin of Latin American Research, v. 32, n. 4, p. 468-82, 2013.

Geddes, Barbara. Politician's dilemma: building State capacity in Latin America. Berkley, Los Angeles, London: University of California Press. 1996.

HUBER, Gregory A. The craft of bureaucratic neutrality. $1^{\text {st }}$ Edition. Cambridge, England; New York: Cambridge University Press. 2007.

LIMA, Maria Regina Soares de. Instituições democráticas e política exterior. Contexto Internacional, v. 22, n. 2, p. 265-303, 2000.

LIMA, Maria Regina Soares de; HIRST, Monica. Brasil como país intermediário e poder regional. In: Os Brics e a Ordem Global. Rio de Janeiro: FGV, p. 43-74, 2009.

LIMA, Rodolfo de Camargo. Burocratas, burocracia e política: o Ministério das Relações Exteriores, um perfil. Dissertação de mestrado: Universidade de São Paulo. 2015.

LOPEZ, Felix Garcia. Evolução e perfil dos nomeados para cargos DAS na administração pública federal (1999-2014)". Brasília: Ipea, 2015.

LOUREIRO, Maria Rita; ABRUCIO, Fernando Luiz. Política e burocracia no presidencialismo brasileiro: o papel do Ministério da Fazenda no primeiro governo Fernando Henrique Cardoso. Revista Brasileira de Ciências Sociais, v. 41, n. 14, p. 69-89, 1999.

Loureiro, Maria Rita; Olivierı, Cecília ; MARTes, Ana Cristina Braga. Burocratas, partidos e grupos de interesse: o debate sobre política e burocracia no Brasil. In: Burocracia e Política no Brasil: desafios para a ordem democrática no século XXI. Rio de Janeiro: FGV, 73-108. 2010.

MINGARDI, Lucas. "O desligamento partidário no contexto brasileiro". In: VIII Seminário Discente da Pós-Graduação em Ciência Política da Universidade de São Paulo. 2018. Disponível em: http://conferencias.fflch.usp.br/sdpscp/viiisddcpusp/ paper/view/2241. 
Moura, Cristina Patriota de. O Instituto Rio Branco e a diplomacia brasileira: um estudo de carreira e socialização. E-Book. Rio de Janeiro: FGV, 2007.

NISKANEN, William A. Bureaucracy and representative government. Chicago: Aldine Atherton. 2007.

OStRoM, Vicent; ELINOR, Ostrom. Public choice: a different approach to the atudy of public administration. Public Administration Review, v. 31, n. 2, p. 203-16, 1971. Peters, B. Guy. The politics of bureaucracy. London; New York: Routledge. 2001.

SCHNEIDER, Ben Ross. Burocracia pública e política industrial no Brasil. São Paulo: Sumaré, Idesp. 1994.

SILvA, Elaini Cristina Gonzaga da; SPÉCIE, Priscila; VITALE, Denise.. Atual arranjo institucional da política externa brasileira. Brasília: Ipea, Texto para iscussão, n. 1489. 2010.

TULLOCK, Gordon. Bureaucracy. Indianapolis: liberty fund.2004.

WAGNeR, Alexander F. Loyalty and competence in public agencies. Public Choice, v. 146, n. 1-2, p. 145-62, 2011.

Weber, Max. Economy and society. 2 vols. Berkley and Los Angeles, California: University of California Press. 1968.

WILSON, James Q.Bureaucracy: what governments agencies do and why they do it. Library of Congress, Basic Books, Inc. 1989.

WISE, Lois Recascino. Bureaucratic posture: on the need for a composite theory of bureaucratic behavior. Public Administration Review, v. 64, n. 6, p. 669-680, 2004.

\section{Rodolfo de Camargo Lima}

Universidad Católica de Temuco (UCT), Chile. Doutor e mestre em Ciência Política pela Universidade de São Paulo. Bacharel em Relações Internacionais pela Pontifícia Universidade Católica de São Paulo. Professor de Ciência Política da Universidad Católica de Temuco (UCT). Coordenador do Mestrado em Governo e Assuntos Públicos (MGAP) da UCT. 